Short Communication

\title{
A high-capacity catechol-based cathode material for rechargeable lithium-ion batteries
}

\author{
Ruiqiang Zhang ${ }^{1}$, Ying Zhang ${ }^{1}$, Xizhong Yin ${ }^{1}$, Zhiying Meng ${ }^{2}, Y_{a}$ Du $^{2, *}$ and Haishen Yang ${ }^{1, *}$ \\ ${ }^{1}$ Shanghai Key Laboratory of Materials Protection and Advanced Materials in Electric Power, \\ Shanghai University of Electric Power, Shanghai 200090, China. \\ ${ }^{2}$ Institute of Advanced Synthesis, School of Chemistry and Molecular Engineering, Nanjing Tech \\ University, Nanjing 211816, China. \\ "E-mail: yanghsh@ shiep.edu.cn, ydu@njtech.edu.cn
}

doi: $10.20964 / 2020.08 .21$

Received: 2 April 2020 / Accepted: 18 May 2020 / Published: 10 July 2020

Using facile acetylene trimerization as a key step, six catechols were congregated on one benzene core to develop a star-shaped redox-active molecule, namely, 3',4',5',6'-tetrakis(3,4-dihydroxyphenyl)[1,1':2',1"-terphenyl]-3,3",4,4"-tetraol, which was termed Cat $_{6} B$. Cat ${ }_{6} B$ demonstrated as a promising cathode material for lithium ion battery with extreme low solubiliy, good cycling stability, and high theoretical specific capacity (442 mAh/g). An initial discharge specific capacity up to $305.2 \mathrm{mAh} / \mathrm{g} @ 50$ $\mathrm{mA} / \mathrm{g}$ and an energy density of $671 \mathrm{Wh} / \mathrm{kg}$ were achieved.

Keywords: organic cathode; catechol; lithium-ion batteries; acetylene trimerization

\section{FULL TEXT}

(C) 2020 The Authors. Published by ESG (www.electrochemsci.org). This article is an open access article distributed under the terms and conditions of the Creative Commons Attribution license (http://creativecommons.org/licenses/by/4.0/). 